\title{
$\operatorname{arCOS} D E S I G N$
}

\section{Mapa-Praça-Máquina: experimentos de design no espaço público}

Barbara Szaniecki (Esdi/UERJ, Brasil)

dolar.rj@terra.com.br

Liana Ventura (Esdi/UERJ, Brasil)

liloaventura@gmail.com

Philippe Leon Anastassakis (Esdi/UERJ, Brasil)

philippeleon@gmail.com

Talita Tibola (Esdi/UERJ, Brasil)

talita.tt@gmail.com

Instituição:

Escola Superior de Desenho Industrial

Universidade do Estado do Rio de Janeiro

Endereço:

Rua do Passeio 80, Lapa

22031-040 Rio de Janeiro, RJ, Brasil 


\title{
Mapa-Praça-Máquina: experimentos de design no espaço público
}

Resumo: A cidade do Rio de Janeiro acaba de passar por um momento de grandes transformações urbanas relacionadas em grande parte ao acolhimento de megaeventos como a Copa do Mundo e os Jogos Olímpicos. A considerável transformação na cidade abriu novas perspectivas, em particular sobre a zona portuária e o centro da cidade, mas também reabriu velhas feridas como a da exclusão social. Concomitante à retirada das grades da Praça Tiradentes, a busca por novas formas de ocupação dos espaços urbanos e das instituições culturais do seu entorno deu início a um processo que levou à realização do conjunto de experimentos de design no espaço público denominado Mapa-Praça-Máquina, numa parceria entre a Escola Superior de Desenho Industrial (ESDI-UERJ), o Centro Municipal de Arte Hélio Oiticica (CMAHO) e o Centro Carioca de Design (CCD) do Rio de Janeiro.

Palavras-chave: Espaço Público; Espaço Comum; Maquinar; Experimentos de Design.

\section{Map-Square-Machine: design experiments in the public space}

\begin{abstract}
The city of Rio de Janeiro has just passed through a moment of great urban transformations related to the host of mega events such as the World Cup and the Olympic Games. The considerable transformation in the city opened up new perspectives, particularly on the portuary zone and the city center, but also reopened old wounds such as social exclusion. Concomitant to the Praça Tiradentes square grids removal, the search for new forms of occupation of the urban spaces and of the surrounding cultural institutions has initiated a process that led to the realization of a set of design experiments in the public space called Map-Square-Machine, a partnership between the Higher School of Industrial Design (ESDI-UERJ), the Hélio Oiticica Municipal Art Center (CMAHO) and the Rio de Janeiro Design Center (CCD) in Rio de Janeiro.
\end{abstract}

Keywords: Public Space; Common Space; Machine; Design Experiments; Design Policies. 


\section{Introdução}

A cidade do Rio de Janeiro acaba de passar por um grande momento de transformação urbana relacionado em grande parte ao acolhimento de megaeventos. O prefeito Eduardo Paes chegou a ser comparado ao Prefeito Pereira Passos tamanha foi a transformação na cidade, abrindo novas perspectivas, em particular da sua zona portuária ao centro da cidade, mas também renovando velhas e graves práticas de exclusão social. Como conseqüência, vivemos o esvaziamento dos espaços públicos o que causa, em particular, a sensação de insegurança. E vice-versa. Contudo, no seio de uma revitalização em parte violenta, abriram-se possibilidades para experiências tão criativas quanto cautelosas, se quisermos fazer uso de expressão de Latour (2008). Trata-se de experiências ainda em busca de conceituação e de oportunidades.

A retirada das grades da Praça Tiradentes junto à busca por novas formas de ocupação da mesma assim como dos espaços culturais do seu entorno marcou o início de um processo que levou à realização de um conjunto de experimentos de design no espaço público denominado MapaPraça-Máquina, fruto deuma parceria entre a Escola Superior de Desenho Industrial (ESDI-UERJ), o Centro Municipal de Arte Hélio Oiticica (CMAHO) e o Centro Carioca de Design (CCD) do Rio de Janeiro.

\section{Praça Tiradentes: espaço público, espaço comum}

Situada no centro do Rio de Janeiro, a Praça Tiradentes participou desse processo de forma singular. Todo seu entorno foi revitalizado com base na instalação de equipamentos culturais e criativos no casario antigo - Centro Municipal de Arte Hélio Oiticica desde 1996, Galeria Gentil Carioca desde 2003, Centro Carioca de Design desde 2010 e Centro Sebrae de Referência do Artesanato Brasileiro desde 2016, entre outros -, ou seja, trata-se de uma revitalização inspirada no modelo de criação de "distritos criativos" fortalecedores da "economia criativa". O florescimento institucional e a renovação do casario colonial, ainda que frágil, trazem um ar primaveril à região. Mas o que é primavera para uns pode ser outono para outros. Em outras palavras, os benefícios à dita classe criativa, nos termos de Richard Florida, trazem consigo riscos de gentrificação. Há discussão em torno do termo, de seus usos e de seus efeitos: alguns afirmam que a ocupação do território por uma nova classe social foi apenas parcial, para fins de trabalho e não de moradia e que, portanto, o fenômeno não afetou a população local, enquanto outros consideram que ocorreu uma revitalização violenta da 
região. O tema merece abordagem cuidadosa mas nossa proposta específica, aqui, é a de observar as práticas de ocupação deste espaço e atuar na convivência dos diferentes modos de vida ali presentes.

Um marco na gestão política deste lugar tão singular foi a decisão da Prefeitura ${ }^{1}$, em 2011, de retirar as grades da praça e, ao mesmo tempo, apostar nas dinâmicas do bairro para a ocupação do espaço público. As grades são de natureza infraestrutural e sua retirada não é mera antiarquitetura ou anti-urbanismo, e sim uma tática política que articula o saber do campo da arquitetura e do urbanismo com o poder público. Em todo caso, ainda que instigante, ela pode se mostrar insuficiente em termos de efeitos. Para além da retirada das grades, poderes públicos e agentes locais perceberam a necessidade de ações de ocupação e, dessa percepção, nasceu a iniciativa Tiradentes Cultural. Como o próprio nome indica, trata-se de um evento mensal de natureza cultural movido, principalmente, por atividades de gastronomia e música. Além disso, o evento, baseado em políticas de editais, conta com uma ampla parceria entre atores locais ${ }^{2}$. Complementares, tanto a opção infraestrutural da praça quanto a ação cultural que ela passou a abrigar, enfrentaram polêmicas. Somente três dias após a retirada das grades, seguindo sua linha editorial costumeira, o jornal carioca O Globo denunciava o "retorno de mendigos" ${ }^{3}$. E essas iniciativas seguem enfrentando os desafios do tempo. A retirada das grades pode não ser definitiva mas já é duradoura, assim como pode ser tida como duradoura a ocupação cultural por meio de política de edital ${ }^{4}$. Tem, contudo, a efemeridade característica dos eventos.

Diante dessas polêmicas e desafios, para além das iniciativas oriundas da arquitetura e do urbanismo, da arte e da cultura, emergiu o desejo de contribuir com design e como designers, não meramente enquanto classe criativa e sim enquanto cidadãos ativos. Pode-se argumentar que o design já vem dando contribuições relevantes nas praças

\footnotetext{
${ }^{1}$ Prefeito inaugura Praça Tiradentes totalmente reformada - sem grades e com espetáculos gratuitos: http://bit.ly/2wwa1u5

2 https://www.facebook.com/tiradentescultural/ Fazem parte da Tiradentes Cultural: Teatro João Caetano, Studio X, Centro Municipal de Arte Helio Oiticica, Escola de Música Villa Lobos, IFCS/UFRJ, A Gentil Carioca, Centro de Arte Maria Teresa Vieira, Galeria Scenarium, Refeitório RJ, Polo Novo Rio Antigo, SEBRAE, Centro Carioca de Design, Largo das Artes, Centro Cultural Carioca e Casa do Choro. ${ }^{3}$ Retirada de grades da Praça Tiradentes e retorno de mendigos reacendem debate sobre estética, lazer e segurança: https://oglobo.globo.com/rio/retirada-de-gradesda-praca-tiradentes-retorno-de-mendigos-reacendem-debate-sobre-estetica-lazerseguranca-2869996

${ }^{4}$ Prefeitura do Rio de Janeiro lança edital para promover atividades na Praça Tiradentes: http://www.archdaily.com.br/br/798532/prefeitura-do-rio-de-janeirolanca-edital-para-promover-atividades-na-praca-tiradentes
} 
cariocas: em termos de infraestrutura, nos equipamentos para crianças e idosos e, em termos de cultura, nos recursos gráficos que valorizam os eventos e seus produtos. Mas a contribuição que propomos vai além e requer um entendimento daquele lugar não apenas como distrito criativo com suas revitalizadas instituições como também enquanto espaço político com novas institucionalidades. Que espaço é esse? Que espaço pode ser?

Em sua tese $O$ Espaço público - arqueologia da publicidade como dimensão constitutiva da sociedade burguesa publicada em 1960, o alemão Jürgen Habermas" aborda a emergência da noção de "espaço público" com base na publicidade. Segundo o filósofo, público e privado se opõem desde o Direito Romano mas tal oposição perde importância na Idade Média e só volta a valer novamente com a constituição de uma esfera da sociedade civil em oposição ao Estado. Essa esfera da sociedade civil pode ser entendida inicialmente como esfera de pessoas físicas que, reunidas em fóruns, no espaço de praças ou cafés, formam uma "opinião pública" questionadora dos poderes mercantis e políticos. Segundo Habermas (1991), o veículo deste questionamento e até de oposição, é a publicidade. A publicidade nasce como um princípio com o qual um público essencialmente burguês controlaria o Estado. A publicidade tenta pôr fim à prática de segredo absoluta típica das monarquias. É somente no século XIX que a publicidade se divide em crítica das pessoas privadas constituídas como público por um lado e, por outro, em condicionamento ou manipulação da mesma, fortalecendo-se também como instrumento comercial.

As noções de "esfera pública" e de "espaço público" se confundem com frequência. A primeira noção nutriu a sociologia moderna, a segunda o urbanismo moderno. E se alimentaram reciprocamente. A esfera pública pode se realizar numa residência ou num bar, mas seu lugar privilegiado é a praça e a rua, isto é, o espaço público. A esfera pública realizada no espaço público tem uma potência considerável e uma de suas expressões máximas são as manifestações populares. Mas hoje encontra um limite justamente por estar atrelada a ideias demasiado modernas, no plano do pensamento e da política, como a de crítica racional e de interesse geral.

Onde as noções de "espaço público" e "espaço comum" se aproximam e onde se diferenciam? Vimos em rápidas linhas a gênese da noção de publicidade que deu origem à noção de espaço público e sua valorização pelo urbanismo moderno. Na era moderna, o espaço público era animado pelos debates suscitados por uma esfera pública unida em sua restrição aos poderes absolutos do Estado. Já a noção de "espaço comum” é inspirada na era pré-capitalista. Na Inglaterra, Commons eram os campos compartilhados pela comunidade. Na contemporaneidade, o termo retorna 
com força pelo entendimento dos diversos atores da sociedade de que não devem se restringir a uma crítica ao Estado e sim se organizar para atingir objetivos comuns; e também pelos desafios do capitalismo contemporâneo, das redes tecnológicas e da crise ambiental. O commons original se desdobra em temas como creative commons (LESSIG, 2004) relacionado aos bens intelectuais, criativos e culturais; como common ressources relacionado não apenas ao compartilhamento da terra, como também ao acesso e à qualidade de recursos como a água dos rios e o ar das florestas (OSTROM, 1990) e commonwealth que contesta a "República da Propriedade" e ensaia possibilidades de um bem estar comum (HARDT e NEGRI, 2009). A partir dessas referências, vemos como a noção de "espaço comum" extrapola a de "espaço público" e é usada correntemente como sinônimo de "espaço autogestionado". A proposta é pertinente e muitos coletivos urbanos têm atuado neste sentido. Aqui, contudo preferimos abrir o leque de atuação para além das ideias de "ativação do espaço público" e de "gestão de espaço comum" e, sem desvalorizar a sua importância, afirmamos o desejo de “maquinar” a Praça Tiradentes com outros atores ou agentes, por meio do design.

\section{Maquinar praças com outros, por meio do design}

Retornemos à Praça Tiradentes, fundamental na proposta de revitalização do centro do Rio de Janeiro. Ela se apresenta hoje como uma praça com caráter monumental muito pouco convidativo ao convívio, mas nem sempre foi assim. No século XVII era conhecida como Rossio Grande e era um largo muito frequentado. No século XIX e, mais precisamente em 1821, quando o príncipe-regente jurou fidelidade à Constituição Portuguesa na sacada do Real Teatro São João, passou a ser chamada de Praça da Constituição e, em 1862, foi inaugurada a estátua de D. Pedro I montado a cavalo. Somente em 1890, dois anos antes do centenário da morte de Tiradentes nos arredores, que a praça ganhou o atual nome. A estátua no centro da praça enfatiza sua forte relação com a política do país. Contudo, para além do papel político, a Praça Tiradentes se afirma no século XX como centro cultural com a instalação dos teatros João Caetano e Carlos Gomes. Neste cenário de representação política e cultural, neste espaço urbano que não acolhe a cotidianidade nem do trabalhador nem do morador, e ainda menos de outros modos de vida às margens - Por um lado, o que o Marc Augé chamaria de um não-lugar, isto é, mera passagem. Por outro, um espaço opaco, nos termos de Milton Santos - o que significa ou pode significar uma 
maquinação? Como fazer da praça monumental uma praça mais convivial, efetivamente viva?

Ao pensar na possibilidade de "maquinar a praça", nos referimos a Félix Guattari que não reduz "máquina” a um artefato técnico, muito pelo contrário, a considera maquinaria indistinta dos componentes individuais e coletivos que a constituem, e muito mais. Mais do que qualquer máquina, lhe interessa o maquínico. Para entender a genealogia dessas reflexões guattarianas, Gerald Raunig vai ao encontro de Marx e de seu famoso Fragmento sobre as Máquinas nos Grundisse. Nele, as poderosas máquinas já não eram limitadas a seus aspectos mecânicos e sim concebidas como assemblagens mecânico-intelectual-social que afetam e são afetadas por trabalhadores e trabalhadoras. E também vai ao encontro de experiências artísticas construtivistas tais como a do Teatro de Trabalhadores de Moscou que inspirou, por sua vez, inúmeras montagens maquínicas desde o teatro de Sergei Tretyakov até o cinema de Sergei Eisenstein.

Contudo, segundo Raunig, Deleuze e Guattari vão além dessas importantes referências. Ao retomar o termo "máquina", questionam os esquemas evolutivos que definem "ferramentas" como extensões dos humanos para mitigar seus esforços e "máquinas" como aquelas que não apenas substituem as ferramentas como também viriam a tornar-se independentes dos humanos. À diferença de Marx, eles retomam uma compreensão pré-moderna em que a distinção entre o orgânico e o mecânico é irrelevante. Para esses autores não se trata, portanto, de avaliar as possíveis correspondências entre homem e máquina, ou substituições de um pelo outro, e sim de provocar a comunicação entre ambos. O homem compõe com a máquina e pode compor com qualquer coisa para constituir uma máquina. As outras coisas podem ser animais, ferramentas, pessoas, frases, signos ou desejos. Enfim, qualquer "coisa" pode constituir-se enquanto máquina por meio de processos de trocas recíprocas, não necessariamente simétricas. Em suma, aqui o pensamento de Deleuze e Guattari aparecem em clara sintonia com as propostas de autores como Bruno Latour e Donna Haraway que têm proposto associações entre humanos e não humanos, e nos têm instigado com práticas que mais se aproximam de um drawing things together (LATOUR, 2012) e de um making string figures (HARAWAY, 2016) do que um design no sentido moderno da produção e da comunicação.

Apesar do chamado desses últimos autores, seguimos com Deleuze e Guattari. Em Mil Platôs, Deleuze e Guattari apresentam um pensamento político - um tratado de nomadologia - baseado na tensão e mesmo no conflito entre "aparelhos de captura" e "máquina de guerra". Distinta da 
instituição militar, esta última é uma invenção de nômades e tem três aspectos: um aspecto espacial-geográfico, um aspecto aritmético ou algébrico e um aspecto afetivo. No que diz respeito ao primeiro aspecto, os autores distinguem sem desconsiderar suas possíveis imbricações, os espaços lisos dos espaços estriados, sendo o mar um exemplo do primeiro tipo e a cidade um exemplo do segundo. A cidade é polis, é polícia, é o espaço do Estado que controla os movimentos e canaliza os fluxos, inclusive do capital. Já sobre o aspecto numérico, os autores afirmam que enquanto o Estado forma exércitos com dezenas, centenas, milhares e milhões, o "número numerante" da máquina de guerra não implica um grau de abstração superior nem quantidades muito elevadas, muito pelo contrário, ele opera com quantidades ínfimas. Também salientam que nessa lógica, não se reparte o espaço para distribuí-lo aos numerosos pois estes se distribuem pelo espaço, ocupando-o.

E, por fim, o aspecto afetivo traz uma distinção entre ferramentas de trabalho e armas de máquinas de guerra em cinco pontos. A diferença de projeção indica que a arma de guerra é projetiva e centrífuga, enquanto a ferramenta de trabalho é introjetiva e centrípeta, no sentido que adapta a matéria a uma forma de interioridade: à do emprego e aos modos de vida que ele constrói. A diferença de vetor afirma que máquina de guerra não tem como modelo a caça, e sim a cavalgadura: enquanto o caçador visa parar o movimento do animal e se apropriar das proteínas de sua carne, o nômade toma de empréstimo ao animal o seu motor. No primeiro caso, temos gravidade, no segundo velocidade. A terceira distinção é a de modelo e afirma que a ferramenta remete ao trabalho assalariado em seu movimento linear de um ponto a outro - de casa ao trabalho, por exemplo - em velocidade relativa, enquanto a arma remete à ação livre em sua ocupação turbilhonar do espaço em velocidade absoluta. A quarta distinção sinaliza que trabalho e ação livre desenvolvem tonalidades passionais de tipo diferente: sentimentos ou afetos. O trabalho mobiliza sentimentos para a organização de uma forma que corresponde à formação do sujeito: o emprego na fábrica corresponde à formação do proletariado da época fordista cuja representação se dava através da carteira de trabalho e da atuação no sindicato entre outras formas. A ação livre libera afetos em sua velocidade que corresponde ao "não-fazer" do guerreiro: as lutas na metrópole correspondem ao informe do precariado da época pós-fordista cuja expressão depende das armas e das "artes" que cria. Chegamos ao quinto elemento diferenciador: trata-se da própria expressão. Enquanto a organização do trabalho tem afinidade com signos da escrita, a ação livre requer jóias de expressão. 
Embora trazidas aqui de forma extremamente sintética, essas considerações trazem algumas pistas de como maquinar com design, em pleno centro do Rio de janeiro, uma praça que perdeu seu caráter político mas que preserva uma centralidade sociocultural, entre novas instituições e ocupações; que é atravessada de lado a lado por pessoas correndo mas que também é habitada em seus quatro cantos por pessoas "em situação de praça”. Paradoxalmente, seguindo Deleuze e Guattari, podemos considerar que aqueles que correm atrás de seus empregos e de seus estudos são sedentários enquanto aqueles espalhados pelos cantos da praça são nômades. A proposta de "maquinação" vai além das ideias e práticas de "gestão" e de "ativação", muitas vezes empregadas de forma hierarquizada entre poder público com suas instituições e sociedade, ou mesmo entre os ditos criativos e os que supostamente não o são. A maquinação convoca a heterogeneidade.

Nossa proposta de maquinação também é inspirada em algumas proposições de Hélio Oiticica. A vitalidade do Centro Municipal de Arte Hélio Oiticica sob gestão de Izabela Pucu com a iniciativa de uma Plataforma de Emergência reunindo por meio de atividades comuns vários programas de pós-graduação em Arte do Rio de janeiro certamente contribuiu, junto com nossa ocupação uma vez por semana daquele espaço, para formular a proposta. De certa forma, o artista nos acompanhava. Os Penetráveis criados por HO nos anos 70 são sempre lembrados mas pouco se fala da importante diferença trazida pelo Penetrável Magic Square, não mais pensado para o espaço institucional e sim para o espaço urbano. Square pode ser traduzido não apenas como "quadrado" mas também como "praça". Alguns críticos associaram o Penetrável aos quadrados de Klee e Mondrian, mas HO insistiu de que se tratava de um quadrado-praça-mágica. Ora, o que mais nos interessa neste quadrado-praça-mágica não é a sua forma quadrada e sim o circular pelo quadrado. Com seu Penetrável Magic Square, HO parece procurar uma experiência urbana ao mesmo tempo mais concreta e mais imaginativa, aberta a possíveis. Com ele, podemos maquinar o pósestruturalismo francês e o neoconcretismo brasileiro e, sobretudo, experimentar fazer da Praça Tiradentes um imenso Penetrável urbano.

Figura 1. Participantes do curso de extensão Mapa-Praça-Máquina "maquinando" seus experimentos (fonte: arquivo pessoal).

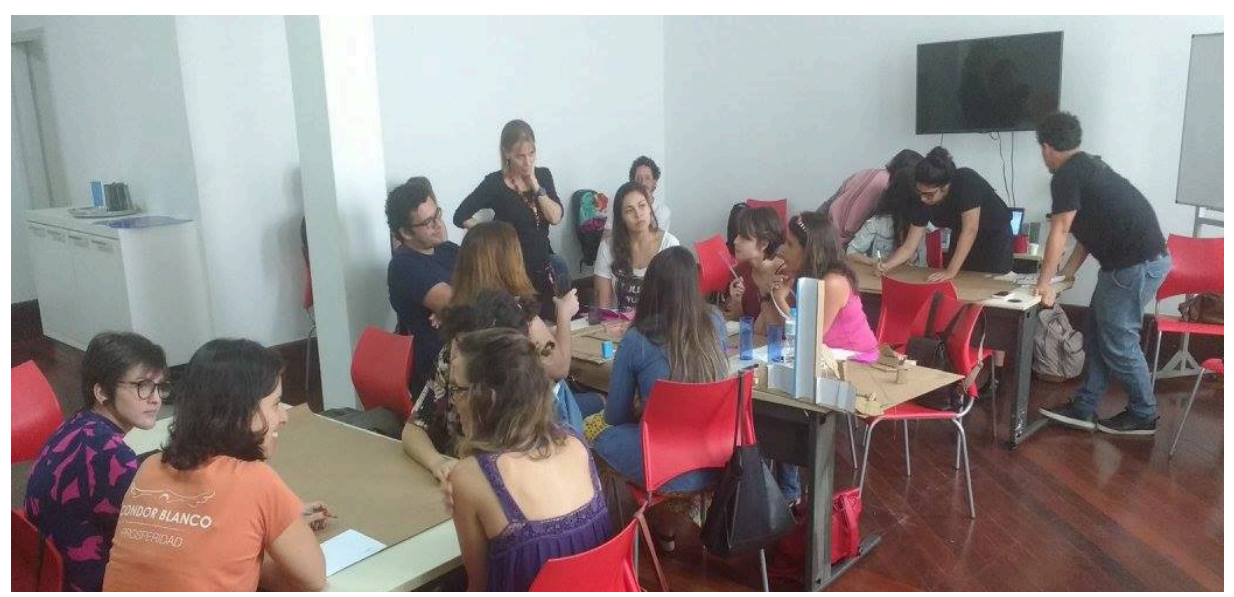




\section{Mapa-Praça-Máquina}

O curso de natureza teórico-prática intitulado "Mapa-Praça-Máquina: experiência de design colaborativo no espaço público" 5 foi realizado como curso de extensão da Escola Superior de Desenho Industrial (ESDI-UERJ) em parceria com o Centro Municipal de Arte Hélio Oiticica (CMAHO), através da sua Plataforma de Emergência. A formatação e a realização do curso de extensão se deu de forma colaborativa envolvendo as professoras coordenadoras Barbara Szaniecki e Talita Tibola, associadas ao Laboratório de Design e Antropologia do PPDESDI/UERJ e seis estudantes da pósgraduação do PPDESDI/UERJ - Liana Ventura e Philippe Leon Anastassakis num primeiro momento; Gianna Larocca, Ewerton Santos Dantas, Romulo Guina e Larisa Paes num segundo momento -, constituindo assim uma equipe total de oito membros atuando como professores. A eles se juntaram os inscritos no curso de extensão e, ao longo do curso, muitos outros maquinantes.

O nome proposto para o curso, definido a partir da costura conceitual dos três elementos - mapa, praça e máquina - procurava apresentar sua proposta de apreensão e ampliação dos múltiplos agenciamentos que produzem a praça e por ela são produzidos. O próprio agenciamento dessas palavras pretendia evocar e incitar o encontro, proposital ou por acaso, de heterogeneidades: o mapa como mote de conversação e captura de informação, a praça como o potencial local desses processos e a máquina, já presente ou ainda por ser construída, como aquela que vem atualizar essa potência. Na mistura desses três termos, procuramos investigar possibilidades para o design e papéis para o designer.

Ao longo de quatro módulos, o curso procurou articular teoria e prática na sala de aula do CMAHO assim como em campo na Praça Tiradentes. E visou, mais especificamente, analisar e experimentar a praça por meio de abordagens vindas dos campos do design, da antropologia e das ciências sociais e políticas. Para isso, buscamos, no módulo I, oferecer aos participantes uma base teórica com conceitos-chave que pudessem de alguma forma nortear as práticas de campo como também, no sentido inverso, permitir às práticas o questionamento dos conceitos selecionados.

\footnotetext{
${ }^{5}$ A estrutura do curso foi dividida em 4 módulos sendo cada um composto por duas aulas, somando 8 aulas de 4 horas cada, num total de 32 horas. O curso de extensão da Esdi/UERJ com inscrição gratuita foi aberto aos estudantes da UERJ, aos freqüentadores do CMAHO e ao público em geral. Pudemos contar com a participação de 27 inscritos dos campos do design, arquitetura, urbanismo e artes visuais, tendo seu inicio em 17 de outubro e finalizado em 12 de dezembro de 2016 O MPM é fruto de uma parceria entre Lada/Esdi, CMAHO e, mais tarde, do CCD.
} 
Os conceitos foram apresentados brevemente sob a forma de verbetes segundo quatro eixos temáticos: espaço, sociedade, design colaborativo e imagem/representação. No encontro seguinte foram retomados de forma lúdica por meio de um jogo - jogo de verbetes - no qual os participantes puderam tecer relações, de oposição ou afinidade, entre os mesmos e as suas próprias vivências de praça. Esses exercícios aproximaram os participantes de alguns conceitos-chave na elaboração de propostas de práticas colaborativas no espaço público e na tessitura de relações frente às linhas de forças ou fragilidades que o atravessam.

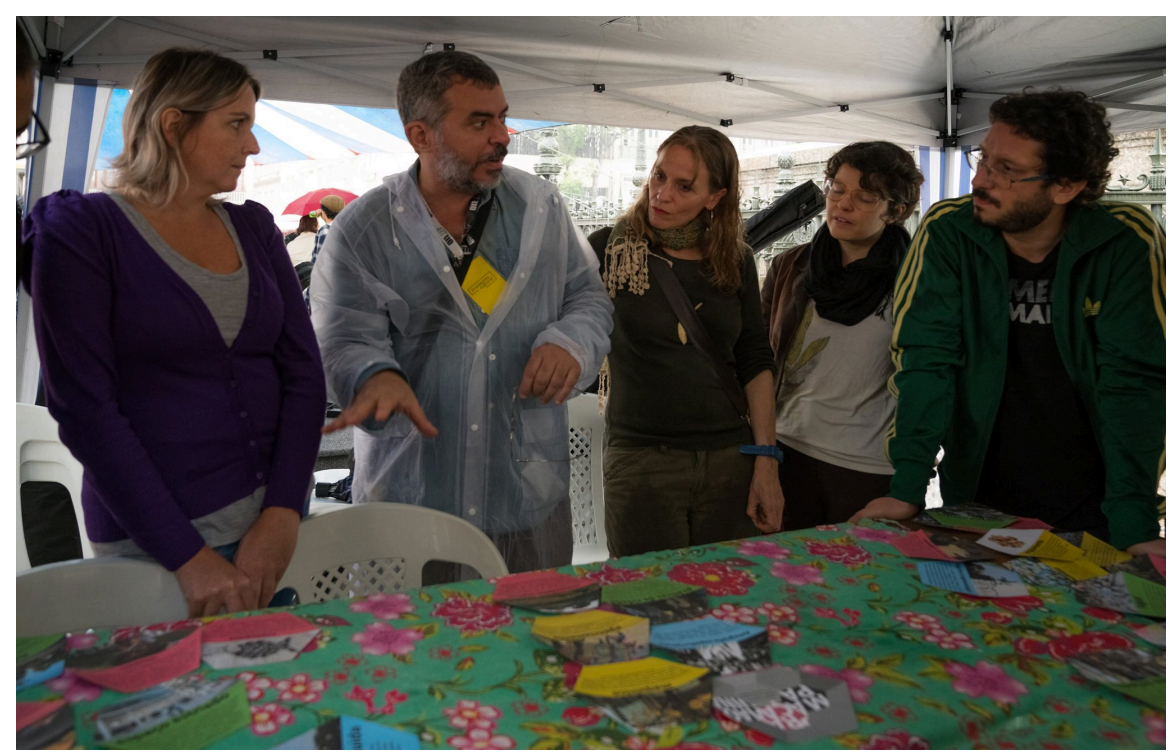

Figura 2. Jogo dos verbetes criado para o Mapa-Praça-Máquina na Tiradentes Cultural (fonte: arquivo pessoal).

Para melhor "armar" os participantes do curso, no módulo II foram apresentadas metodologias de pesquisa de campo e metodologias de análise dos resultados tais como sínteses visuais acerca das questões formuladas por cada grupo. As sínteses foram construídas colaborativamente, utilizando uma metodologia de visualização denominada modelo-mapa. Tratava-se de representar uma questão e os afetos que a atravessam por meio da construção de uma miniatura física tridimensional de baixa resolução, isto é, de realização rápida e criativa, que não demandasse conhecimentos prévios de modelagem e utilizasse materiais simples como papelão, fita adesiva, barbantes e canetinhas. Essa metodologia visou auxiliar os participantes na tangibilização dos dados obtidos em campo por meio de práticas etnográficas e cartográficas. É todavia importante que todas essas metodologias não foram "aplicadas" ao campo de modo asséptico, isto é, elas eram suficientemente abertas para permitir que o campo as "contaminasse" e as transformasse de alguma maneira. 


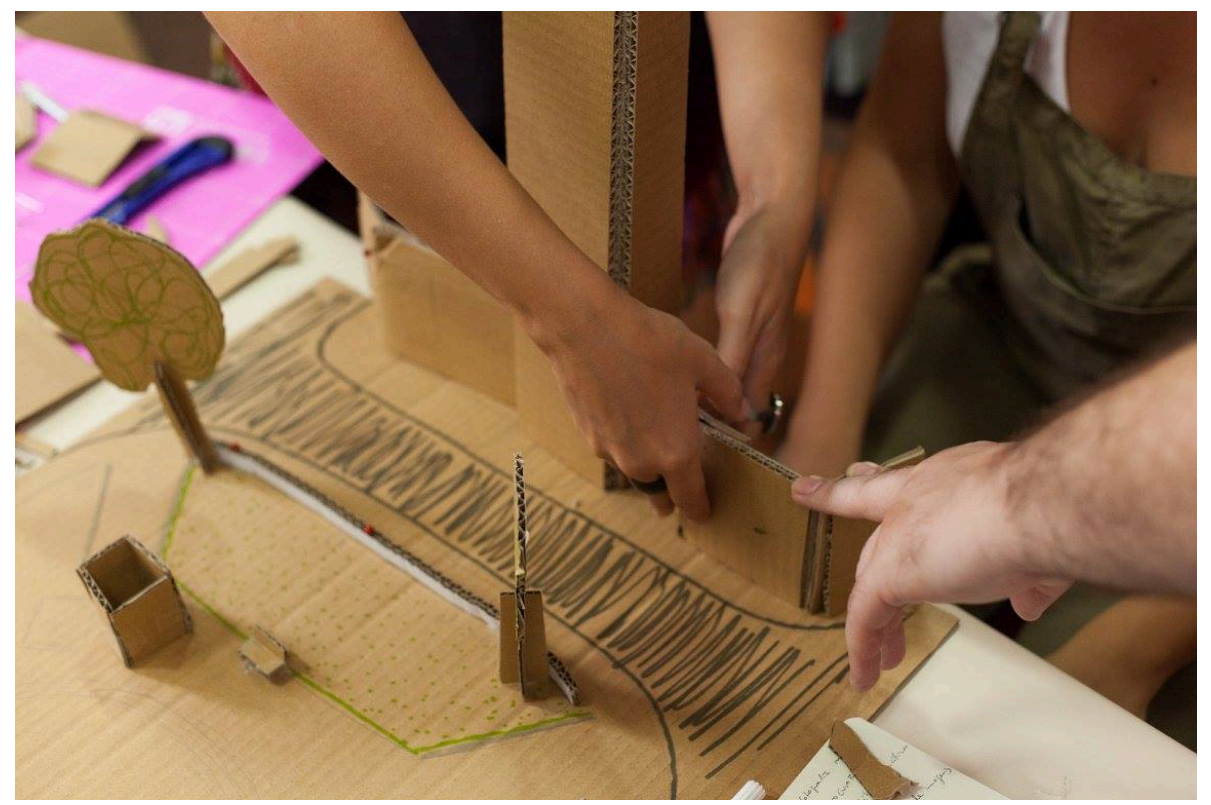

Figura 3. Metodologia Modelo-Mapa utilizada no Mapa-Praça-Máquina para apreender as relações entre o espaço e atores da Praça Tiradentes.

(fonte: arquivo pessoal).

A partir do módulo III passamos a trabalhar com metodologias que pudessem testar em campo, sob a forma de experimentos, algumas das reflexões feitas em sala de aula. Nesse sentido, a ênfase recaiu sobre a potencialidade de troca e engajamento entre os participantes do curso e os sujeitos da praça Tiradentes, passantes e ocupantes. Sempre pensando em como apreender as "práticas de praça", apresentamos metodologias baseadas em jogos exploratórios de design com o objetivo de abrir ambientes propícios a trocas. Assim os grupos foram estimulados a desenvolver jogos capazes de engajar pessoas numa conversa ou convívio, mesmo que rápido, considerando a criação de imagens e cenários - entre outras "coisas" - como suporte para tais interações. Algumas diretrizes foram delineadas: o dispositivo deveria ser apresentado por meio de uma materialidade física, possuir um conjunto de regras simples e um sistema de registro de imagens como forma de documentação do processo. Nosso objetivo geral consistia no estímulo à reflexão sobre as possibilidades de experiências de partilha do espaço público onde os participantes não são definidos a priori. Sendo assim, o maior desafio foi o de criar táticas capazes de efetuar o convite, exigindo por parte dos participantes sensibilidade na escolha de linguagens que potencializassem o engajamento dos diversos passantes e ocupantes da praça tornando-os, por sua vez, maquinantes. 
Por fim, o módulo IV foi dedicado à consolidação dos conhecimentos produzidos até então e desenvolvimento de propostas para a praça. Assim, cada grupo elaborou uma primeira proposta de intervenção no espaço explorando as metodologias apresentadas e as maquinarias criadas e, após análise dos resultados obtidos, elaborou uma segunda proposta, mais madura. A segunda fase dos experimentos se deu em dois momentos. O primeiro aconteceu durante o evento Tiradentes Cultural, a convite de Paula de Oliveira Camargo, gestora do Centro Carioca de Design e também uma das principais articuladoras do evento mensal. Os participantes tiveram a oportunidade de "testar" seus experimentos no mesmo campo mas em um contexto diferente do trabalhado no cotidiano. O segundo momento se deu em dia regular de atividades na praça. As experimentações em circunstâncias bem diferentes enriqueceu as observações finais principalmente no que toca às formas de abordagem e os níveis de engajamento dos participantes. Ao final do curso cada grupo preparou uma apresentação e compartilhou seus aprendizados.

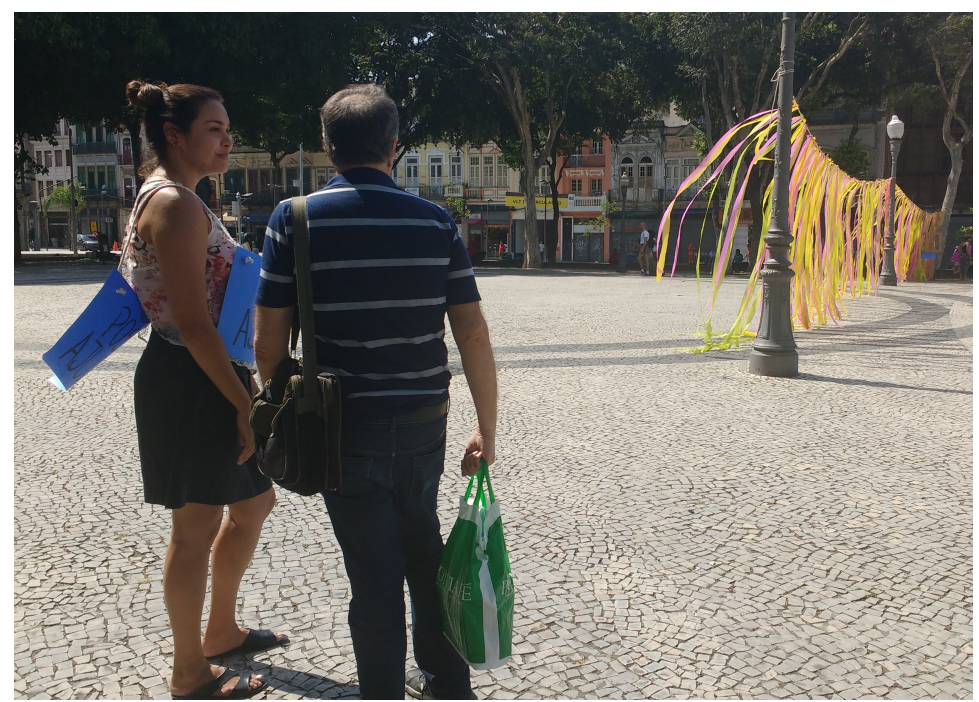

Figuras 4 e 5.

Experimentos do dia-a-dia: maquinando com atores locais.

(fonte: arquivo pessoal).

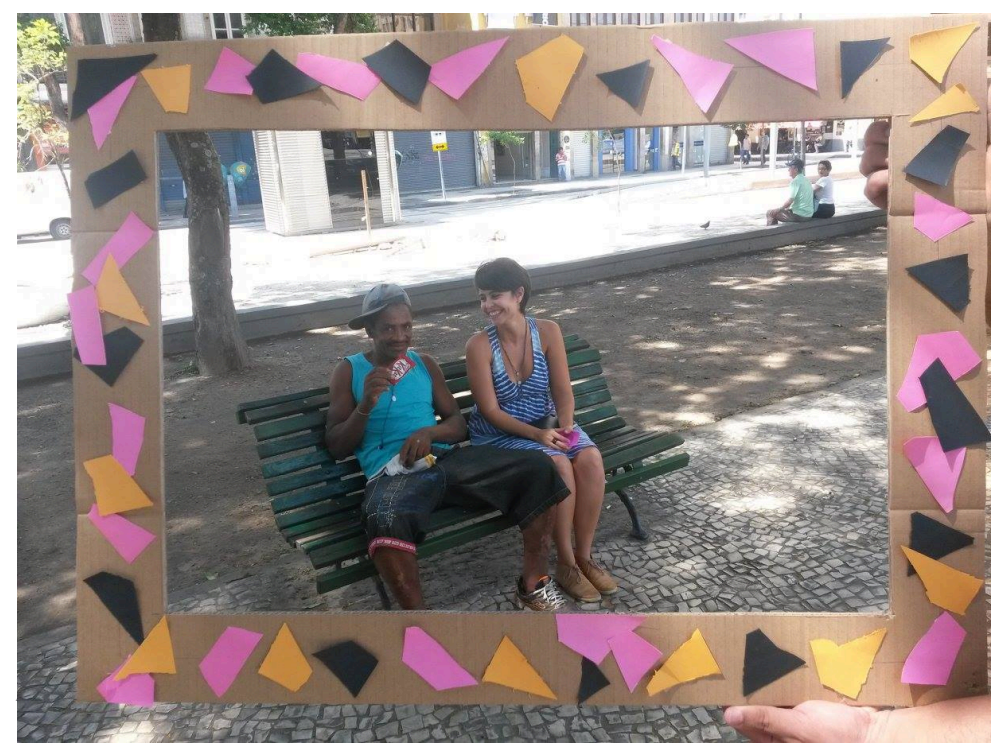


Assim, a análise dos processos ao longo de oito aulas, além de estimular o espírito crítico e criativo dos participantes, pôde levantar importantes reflexões sobre as possibilidades de "maquinação" com design no/do espaço dito público. Mas a perspectiva do comum nos sentidos apontados anteriormente - dos commons urbanos e dos commons criativos e cognitivos (creative commons), dos commons ressources enquanto bens naturais mas também como recursos culturais e, finalmente de um commonwealth como bem estar social baseado no convívio compartilhado no cotidiano - ainda parece uma distante realidade.
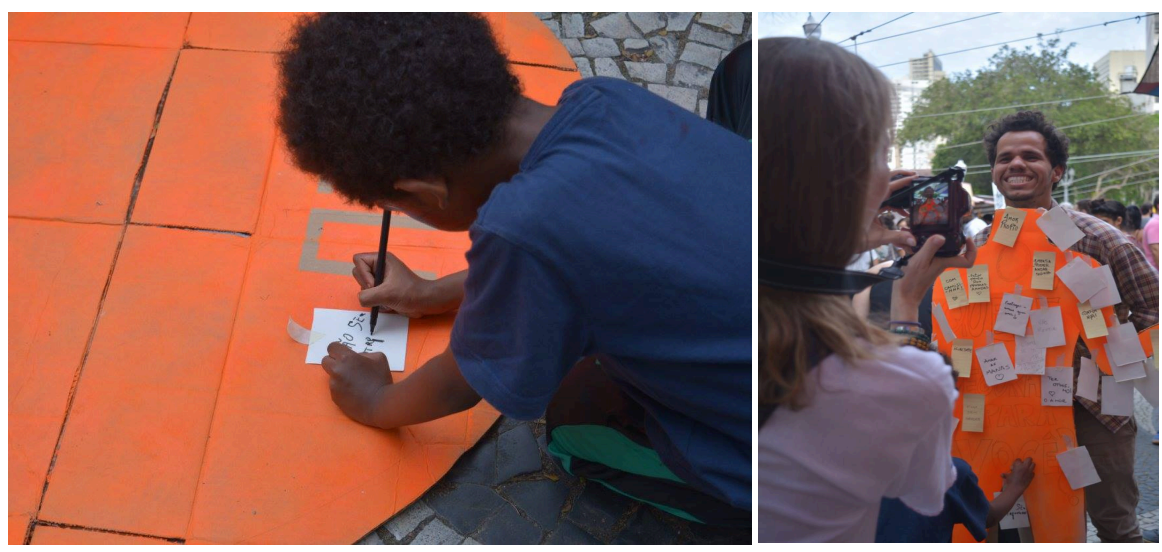

Fig 4 e 5. Experimentos no dia do evento Tiradentes Cultural. (fonte: arquivo pessoal)

\section{Considerações finais}

Ao final do curso Mapa-Praça-Máquina ${ }^{6}$, as possibilidades mas também os problemas da praça ganharam contornos mais nítidos. No cotidiano, a enorme praça monumental é atravessada por pessoas apressadas com suas obrigações, aborrecidas pela espera no ponto de ônibus ou sofridas em sua sobrevivência num canto de banco. É enorme a dificuldade de trazer essas pessoas para uma conversa ou para uma atividade qualquer: por pressa ou por indiferença, poucos param. Os pombos são testemunhas. O espaço é enorme e o tempo é o do corre-corre. Por ocasião da Tiradentes Cultural, para a qual fomos convidados, tudo se transforma. Entre comidas apetitosas e música alta, os participantes do curso realizaram suas propostas. O espaço e o tempo se tornaram aconchegantes assim como se tornaram muitos os maquinantes, de todas as idades mas talvez não tão heterogêneos do ponto de vista social.

\footnotetext{
${ }^{6} \mathrm{Um}$ detalhamento do curso, com relatos e imagens, será publicado em breve como zine independente e disponibilizado na próxima edição da Revista Arcos Design.
} 
No dia a dia, as maquinações seguem efêmeras, frágeis. Apreendemos o tempo do cotidiano e o tempo dos eventos mensais na praça. Tempo linear e tempo pontual: se complementam mas permanecem sem espessura. Ora, qual é o tempo das maquinações, o tempo para que elas atualizem possíveis comunidades? Se nos detemos anteriormente no lugar, chegou a hora de também dirigir atenção ao tempo. E tempo é inseparável de política. O curso se encerrou deixando uma vontade de mais políticas públicas... não apenas para o design como, sobretudo, com design. Políticas que possibilitem uma maior permanência no tempo e no lugar. Políticas que compatibilizem o espaço patrimonializado com outros usos possíveis do mesmo. Políticas que articulem a forma estática das instituições com a fugacidade dos movimentos dos cidadãos. Em suma, políticas de cidadania com design, em trânsito contínuo entre a Praça Tiradentes e as instituições - tais como Centro Carioca de Design e Centro Municipal de Arte Helio Oiticica entre outras - e iniciativas locais. Mais Mapa-Praça-Máquina.

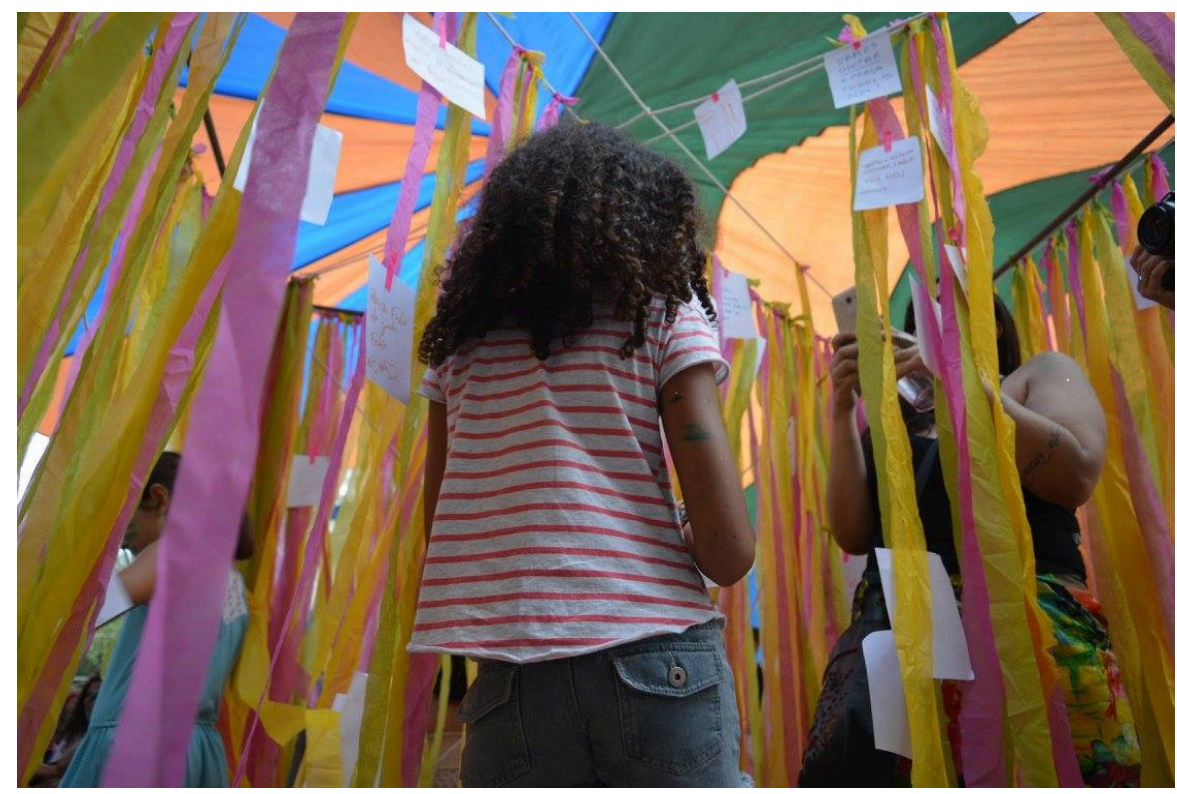

Figura 8. Experimentos no dia do evento Tiradentes Cultural.

(fonte: arquivo pessoal).

\section{Referências}

ANASTASSAKIS, Zoy. SZANIECKI, Barbara. Conversation Dispositifs: towards a transdisciplinary design anthropological approach. In: Design Anthropological Futures organizado por Rachel Charlotte Smith, Kasper Tang Vangkilde, Mette Gislev Kjaersgaard, Ton Otto, Joachim Halse, Thomas Binder. London, New York: Bloombsbury, 2016. 
DELEUZE, Gilles e GUATTARI, Félix. Mil Platôs: capitalismo e esquizofrenia. São Paulo: editora 34, 1997.

GUATTARI, Félix. Caosmose. Paris: Galilée, 1992.

HARAWAY, Donna. Staying with the trouble: making kin in the Chthulucene. Durham and London: Duke University Press, 2016.

HARDT, Michael. NEGRI, Antonio. Commonwealth. Cambridge, Massachussets: The Belknap Press of Harvard University, 2009.

LATOUR, Bruno. Um Prometeu cauteloso? Alguns passos rumo a uma filosofia do design (com especial atenção a Peter Slotedijk). Palestra para o encontro Networks of Design, da Design History Society. Falmouth, Cornualha, 3 de setembro de 2008. http://bit.ly/2xf35kt

LATOUR, Bruno. Reagregando o social: uma introdução à teoria do ator-rede. Salvador, Bauru: Edufba e Edusc, 2012.

LESSIG, Lawrence. Cultura Livre: como a mídia usa a tecnologia e a lei para barrar a criação cultural e controlar a criatividade. Acessível em: http://bit.ly/2xRUc0N

OSTROM, Elinor. Governing the Commons. N. York: Cambridge University Press, 1990.

RAUNIG, Gerald. Algunos fragmentos sobre las máquinas em revista Brumaria - arte, máquinas, trabajo inmaterial, número 7, dezembro 2.

SZANIECKI, Barbara. Penetrável Rio de Janeiro: seja gari, seja herói. In: COCCO, Giuseppe e SZANIECKI, Barbara (organizadores) e PUCU, Izabela (em colaboração). Helio Oiticica para além dos mitos - seminário internacional. Rio de janeiro: centro Municipal de Arte Helio Oiticica, 2016. 


\section{Como citar}

AMARAL, Liana V.; ANASTASSAKIS, Philippe; SZANIECKI, Barbara. TIBOLA, Talita. Mapa-Praça-Máquina: experimentos de design no espaço público. Arcos Design. Rio de Janeiro: PPD ESDI UERJ. Edição especial Outubro 2017. pp. 163-179. Disponível em: [http://www.e-publicacoes.uerj.br/index.php/arcosdesign]

DOI 10.12957/arcosdesign.2017.30947

\section{(c) (1) (8)(2)}

A Revista Arcos Design está licenciada sob uma licença Creative Commons Atribuição - Não Comercial - Compartilha Igual 3.0 Não Adaptada. 